\title{
The importance of optimizing rates of successful stone treatment
}

\author{
Andrea G. Lantz Powers, MD, MEd, FRCSC
}

Department of Urology, Dalhousie University, Halifax, NS, Canada

Cite as: Lantz Powers AG. The importance of optimizing rates of successful stone treatment. Can Urol Assoc J 2021;15(8):259-60. http://dx.doi.org/10.5489/cuaj.7493

See related article on page 255

I $\mathrm{n}$ this issue of CUAJ, Hoare and colleagues describe an interesting retrospective study assessing success rates of ureteroscopy (URS) after a failed attempt requiring stenting for passive dilation. ${ }^{1}$ This study compares "accelerated" stent duration ( $<14$ days) vs. "normal" stent duration (14 days or longer). This is a topic that I think is often on the minds of urologists when they are unsuccessful at accessing the ureter during URS due to narrow ureters, spasm, or tortuosity. As noted by the authors, there is a relative dearth of evidence for treating this patient population regarding the optimal timeline of when to schedule the repeat procedure. I think most of us use a conventional wait time as opposed to anything evidence-based because of the lack of literature on this subject.

The primary outcome of the study was to assess the $8 \%$ of patients (119) with failed URS to determine if shorter duration of stenting (10-13 days) was equivalent to 14 days or longer of stenting. The authors found that success rates were very high (99.2\%) with just one failure and that a stent duration of 10-13 days was as successful as 14+ days. The failure was in the normal stent duration group. The report, however, does not report the median or mean stent duration of each group. Looking at Fig. 1, we can see that most patients in the accelerated stent duration group ( $<14$ days) had their repeat procedure on day 12-13. Is there a statistically significant difference in stent duration between these two groups? I also wonder if that is actually a clinically significant difference in stent duration with respect to the effect on ureteral dilation. I am sure patients would say it makes a difference for them to have the stent in for even a few days less. Despite the study limitations, this remains an interesting and thought-provoking study and it would be useful to see a followup study, ideally a randomized controlled trial, assessing shorter stent duration such as seven days vs. 14 days.

There are several factors that have not been addressed by or reported in this study that would be interesting to know or study in the future (see below).

\section{Equipment}

In endourology, size matters. What scopes were used during these cases? Was there a difference size of scope in failed URS vs. successful URS prior to having to stent for passive dilation?

During residency, I didn't pay much attention to scope size. As a staff member, I certainly do, and try to make sure my residents pay attention to equipment size and teach them to pay attention to what they are using and know what options exist. Due to the durable nature of semi-rigid ureteroscopes, at my institution we have a fleet of massive, old scopes that I hate using and a handful of newer scopes, most of which are still relatively old but are narrower in diameter. The nurses all know my preference for the "newer" scopes and are used to my whining if we run out of them. Thankfully, we are in the process of updating our scopes and, hopefully, our administration will be on board with investing in new, upgraded semi-rigid ureteroscopes soon.

\section{Size of flexible ureteroscope}

Size is also an issue, with digital scopes typically being wider in diameter than fibreoptic scopes. ${ }^{2}$ One study showed that digital scopes can fail to reach stones in up to $10 \%$ of cases (either due to difficulty inserting them or lack of maneuverability, mainly for lower pole stones). ${ }^{3}$ Having backup fibreoptic flexible ureteroscopes in those cases can mean the difference in stenting and coming back and a successful procedure. The smallest fibreoptic scopes on the market now in Canada, to my knowledge, are the Storz Flex-X2S with an outer diameter of $7.5 \mathrm{Fr}^{4}$ and distal tip $6.6 \mathrm{Fr}$, and the Olympus URF-P6 with an outer diameter of $7.95 \mathrm{Fr}$ and distal tip of only $4.9 \mathrm{Fr}^{5}{ }^{5}$ In contrast, the Olympus URF-V2 digital ureteroscope has a tip size of $8.2 \mathrm{Fr}$ and outer diameter of $8.4 \mathrm{Fr}^{6}$

\section{Balloon dilation}

Balloon dilation has been shown to be a safe and effective way to reach stones otherwise inaccessible either due to stricture or a narrow ureter. 7,8 I have wondered in my own practice if I underuse this technique, but I just can't bring myself to do it unless I am treating a stricture. I always tell 
the residents that I wouldn't want my ureter balloon dilated if I could avoid it, so I don't do it to my patients. However, I have also never had a stent before, so I have not personally experienced the reduced quality of life stents can cause, nor have I needed time off work due to a stent. Maybe I would revise my opinion on balloon dilation if I had that experience.

One concern I have with balloon dilation is that, although it is reportedly safe, contemporary stricture rates following URS are typically quite low (often $<1 \%$ to up to $3 \%$ ). ${ }^{9,10}$ It would take a fairly large study population to be adequately powered to identify if stricture rates differ significantly with balloon dilation to prevent a failed URS vs. passive dilation. For now, I will continue to balloon dilate judiciously and mainly reserve it for treating strictures, but it is an area that likely deserves further study.

\section{Alpha-blocker use}

The study by Hoare et al did not assess the use of preoperative alpha-blockers prior to URS, nor did authors report if alpha-blockers were used to try to improve success rates of the repeat procedure. Dr. Pace and colleagues have conducted a meta-analysis of preoperative alpha-blocker use before URS for ureteral stones and found that preoperative use of tamsulosin prior to URS resulted in decreased need for ureteral dilation $(61 \%$ risk reduction; relative risk [RR] $0.39,95 \%$ confidence interval $[\mathrm{Cl}] 0.31-0.48, \mathrm{p}<0.00001$ ), increased ability to reach the stone (RR $1.16,95 \% \mathrm{Cl} 1.10$ $1.23), p<0.00001)$, increased stone-free rate (RR $1.17,95 \%$ Cl 1.08-1.26) at four-week followup, shorter operative time (weighted MD $-6.05,95 \% \mathrm{Cl}-10.17$ to $-1.93 \mathrm{~min}, \mathrm{p}=0.004$ ), and shorter length of stay (MD $-0.34,95 \% \mathrm{Cl}-0.55$ to -0.13 ] days, $\mathrm{p}=0.001){ }^{11}$

I have personally started using preoperative, off-label tamsulosin for many of my URS cases and use them almost routinely for stented patients who either need to come back to the operating room for a secondary procedure or for relief of stent discomfort following successful URS. Perhaps failure rates could be lessened with alpha-blocker use? This is another area I think requires further study; however, as an off-label use, conducting a well-designed, randomized controlled trial is challenging would likely require Health Canada approval. This may be an interesting question for a multicentre, Canada-wide study.

\section{Conclusion}

Hoare et al have reported an interesting study that is thoughtprovoking and highlights multiple questions for further study. I think we owe it to our patients to investigate these questions further and continue work to minimize the qualityof-life impairment patients may suffer from failed URS and ureteral stents. We need to highlight to administrators both the healthcare utilization and cost to society arguments to ensure we optimize rates of successful stone treatment in a timely fashion that minimizes patient morbidity. This work includes lobbying our administration and those managing budgets to stay up to date with our surgical equipment.

Competing interests: The author does not report any competing personal or financial interests related to this work.

\section{References}

1. Hoare DT, Wollin TA, De $S$, et al. Success rate of repeat flexible ureteroscopy following previous failed access: An analysis of stent duration. Can Urol Assoc J 2021;15:255-8. http://dx.doi.org/10.5489/ cuaj.7064

2. Gridley CM, Knudsen BE. Digital ureteroscopes: Technology update. Res Rep Urol 2017;9:19-25. https://doi.org/10.2147/RRU.S104229

3. Shah $K$, Monga M, Knudsen B. Prospective randomized trial comparing 2 flexible digital ureteroscopes: ACMI/Olympus Invisio DUR-D and Olympus URF-V. Urology 2015;85:1267-71. https://doi.org/10.1016/j.urology.2014.12.012

4. Storz. Flexible uretero-renoscope. Available at: https://www.karlstorz.com/cps/rde/xbcr/karlstorz assets/ASSETS/3466709.pdf. Accessed June 25, 2021.

5. Olympus. Flexible fiberoptic ureteroscope. Available at: https://medical.olympusamerica.com/products/ ureteroscope/fiberscope-urf-p5. Accessed June 25, 2021.

6. Olympus. Flexible video ureteroscope. Available at https://olympusmedical.com.sg/products/all-products/endoscopes/ureterorenoscopes/urf-v2-v2r/index.html. Accessed June 25, 2021.

7. Bourdoumis A, Tanabalan C, Goyal A, et al. The difficult ureter: stent and come back or balloon dilate and proceed with ureteroscopy? What does the evidence say? Urology 2014;83:1-3. https://doi. org/10.1016/i.urology.2013.08.073

8. Kuntz NJ, Neisius A, Tsivian M, et al. Balloon dilation of the ureter: A contemporary review of outcomes and complications. J Urol 2015;194:413-7. https://doi.org/10.1016/i.juro.2015.02.2917

9. Cooper JL, François N, Sourial MW, et al. The impact of ureteral access sheath use on the development of abnormal postoperative upper tract imaging after ureteroscopy. J Urol 2020;204:976-81. https://doi.org/10.1097/JU.0000000000001147

10. Stern KL, Loftus CJ, Doizi S, et al. A prospective study analyzing the association between high-grade ureteral access sheath injuries and the formation of ureteral strictures. Urology 2019;128:38-41. https://doi.org/10.1016/i.urology.2019.02.032

11. Alsaikhan B, Koziarz A, Lee JY, et al. Preoperative alpha-blockers for ureteroscopy for ureteral stones: A systematic review and meta-analysis of randomized controlled trials. J Endourol 2020;34:33-41. htrps://doi.org/10.1089/end.2019.0520

Correspondence: Dr. Andrea G. Lantz Powers, Department of Urology, Dalhousie University, Halifax, NS, Canada; andrea.lantz@gmail.com 